\title{
A Comparison of Solubility of Endosequence Root Repair Material Fast Set Putty and Mineral Trioxide Aggregate: An in Vitro Study
}

\author{
Kausar Banu ${ }^{1 *}$, Swathi, MDS ${ }^{2}$, Rajaram Naik MDS ${ }^{3}$
}

${ }^{1}$ Post Graduate Student, Department of Conservative Dentistry and Endodontics, A.J. Institute of Dental Sciences, NH-66, Near Kuntikana Road, Kuntikana, Mangalore, Karnataka 575004, India

${ }^{2}$ Reader, Department of Conservative Dentistry and Endodontics, A.J. Institute of Dental Sciences, NH-66, Near Kuntikana Road, Kuntikana, Mangalore, Karnataka 575004, India

${ }^{3}$ Head of the Department, Department of Conservative Dentistry and Endodontics, A.J. Institute of Dental Sciences, NH-66, Near Kuntikana Road, Kuntikana, Mangalore, Karnataka 575004, India

DOI: 1 10.36348/SJODR.2019.v04i10.009 $\quad$ | Received: 20.10.2019| Accepted: $27.10 .2019 \mid$ Published: 30.10 .2019

*Corresponding author: Kausar Banu

\section{Abstract}

Aim: The aim of this study is to compare the Solubility of Endosequence root repair material fast set putty and Mineral Trioxide Aggregate Angelus (MTA-Angelus). Methods and Material: Solubility was determined by preparing stainless steel ring molds which were filled with cements corresponding to two groups $(n=5)$. Samples were transferred to bottles containing $10 \mathrm{ml}$ of distilled water and stored at $37^{\circ} \mathrm{C}$ for 1,7 , and 21 days. Solubility was measured as the difference between the initial weight and the weight at the end of each storage period. Results were analyzed using Mann Whitney U test and Wilcoxon signed rank sum test. Results: The results showed weight loss with time for both materials. The solubility of ERRM and MTA on 21 days was more compared to its solubility after 1 and 7 days. Conclusions: There was no significant difference in solubility between endosequence root repair material and mineral trioxide aggregate.

Keywords: Endosequence root repair material, Mineral trioxide aggregate angelus, Root end filling material, Solubility.

Copyright @ 2019: This is an open-access article distributed under the terms of the Creative Commons Attribution license which permits unrestricted use, distribution, and reproduction in any medium for non-commercial use (NonCommercial, or CC-BY-NC) provided the original author and source are credited.

\section{INTRODUCTION}

Most endodontic failures occur as a result of leakage of irritants from pathologically involved root canals [1]. An annual estimation of endodontic procedures suggests that approximately $5.5 \%$ of all treatments performed involve root end surgery and root perforation repair ${ }^{2}$. Root end filling materials should create a seal, thus avoiding bacterial infiltration and diffusion of bacterial toxins from the root canal system to periradicular tissues [3]. Amongst other desirable properties it should also be dimensionally stable, nonabsorbable, not affected by the presence of moisture, and insoluble [4, 5]. Lack of solubility has been mentioned as one of the ideal characteristics of root-end filling material [6]. ISO 6876 standard places the acceptable limit of weight loss for solubility test at $3 \%$ [7].

Several materials have been used as root repair and root end filling materials. Therefore, these materials include amalgam, resin composites, ethoxybenzoic acid cements, Cavit, glass ionomer cements, gutta-percha, zinc oxide eugenol cements, polycarboxylate cements, and Mineral Trioxide Aggregate (MTA) [8]. But ever since the advent of MTA in 1990 the changes have been revolutionary as MTA has shown to have excellent bonding strength, shown to form dentin bridge and has virtually corrected all the problems associated with earlier materials [9]. However, MTA has exhibited specific disadvantages of long setting time and difficult handling characteristics [10].

However the mankind always strives for perfection and so do the researchers who have led to the development of new material like Endosequence Bioceramic Root Repair Material (ERRM) used for perforation repair, apical surgery, apical plug, and pulp capping. It is a premixed cement that is available as a paste, condensable putty and, more recently, a syringable fast set putty that sets in 20 minutes with easier handling and application when compared to MTA [9]. Solubility is the mass loss of a material during a period of immersion in water. Moreover, solubility may be a cause of disintegration or degradation of the root-end filling material, thereby leaving spaces that may provide gaps for bacterial colonization and their passage in periapical tissue [11]. Studies done by Poggio et al., [12], Torabinejad et al., [13] and Danesh et al., [14] have established low or no 
solubility of mineral trioxide aggregate (MTA). No studies have reported solubility of ERRM. Therefore, the aim of this study is to evaluate the solubility of ERRM in comparison to MTA over a period of 1,7 , and 21 days.

\section{MATERIALS AND METHODS}

Solubility of Angelus MTA (Angelus, Londrina, Brasil) and Endosequence root repair material fast set putty (BRASSELER, USA) (Table-1), in distilled water were evaluated after 1,7 and 21 days storage period.

Table-1: Chemical composition of MTA Angelus and ERRM fast set putty

\begin{tabular}{|c|c|c|}
\hline Material & Composition & Manufacturer \\
\hline MTA ANGELUS & $\begin{array}{l}\text { Tri Calcium Silicate } \\
\text { Dicalcium Silicate } \\
\text { Tri Calcium Aluminate } \\
\text { Tri Calcium Oxide } \\
\text { Bismuth Oxide }\end{array}$ & $\begin{array}{l}\text { ANGELUS, LONDRINA, } \\
\text { BRASIL }\end{array}$ \\
\hline $\begin{array}{l}\text { ERRM } \\
\text { FAST SET PUTTY }\end{array}$ & $\begin{array}{l}\text { Calcium Silicates } \\
\text { Monobasic Calcium Phosphate } \\
\text { Tantalum Oxide } \\
\text { Zirconium Oxide } \\
\text { Proprietary Fillers } \\
\text { Thickening Agents. }\end{array}$ & BRASSELER, USA \\
\hline
\end{tabular}

Circular stainless steel ring molds with an internal diameter of $15 \pm 0.1 \mathrm{~mm}$ and a height of $1.5 \pm 0.1 \mathrm{~mm}$ were used for sample preparation (Figure 1A). The ring molds were filled with test materials/cements corresponding to two groups $(\mathrm{n}=5)$. The discs were placed in $100 \%$ humidity for 24 hours. Then, it was stored individually in plastic bottles containing $10 \mathrm{ml}$ of distilled water at $37^{\circ} \mathrm{C}$ (Figure-1B).

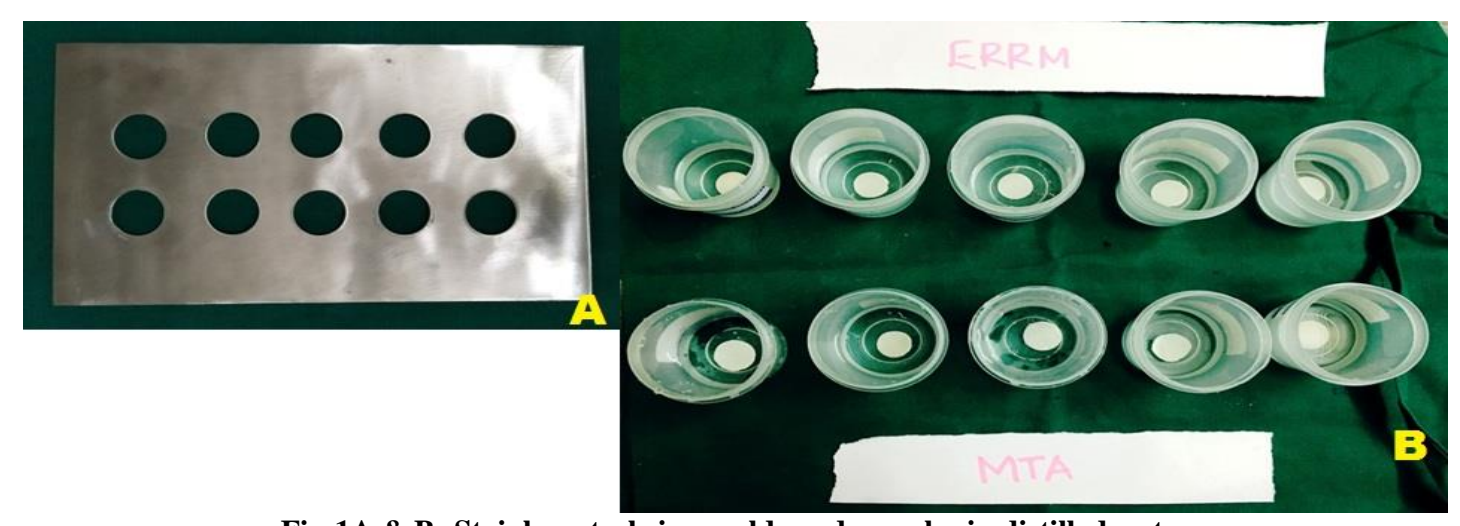

Fig-1A \& B: Stainless steel ring molds and samples in distilled water

Before every testing period (1, 7, 21 days), the discs were desiccated using a desiccation container and placed in an oven with a constant temperature of $37^{\circ} \mathrm{C}$ for 1 hour. Then, each disc was weighed to the nearest microgram. After weighing, each disc was returned to the same container. The water in the containers was neither changed nor was there any addition during the test periods. Mixing and weighing of the samples were performed by a single operator at $23 \pm 2^{\circ} \mathrm{C}$ and a relative humidity of $50 \pm 5 \%$. Data was analyzed using
Wilcoxon signed rank sum test and Mann-Whitney U test.

\section{RESULTS}

The results showed weight loss with time for both materials the total weight loss of ERRM was 0.187 mg on 21 days, while MTA had a total weight loss of $0.173 \mathrm{mg}$. 


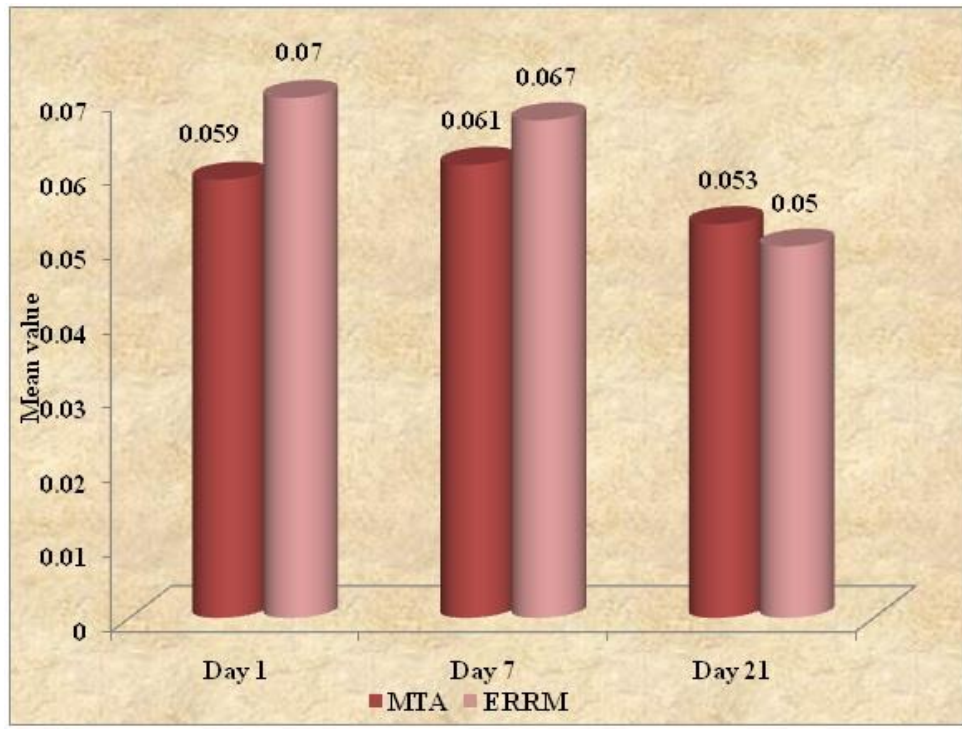

The solubility of ERRM on 21 days was more compared to its solubility after 1 and 7 days. Similarly, MTA showed more solubility on 21 days compared to 1 and 7 days as shown in Table- 2 .

Table-2: Mean values and standard deviation of solubility of MTA and ERRM after 1, 7, and 21 days

\begin{tabular}{|c|c|c|c|c|}
\hline Duration & Group & N & Mean & $\begin{array}{c}\text { Std. } \\
\text { Deviation }\end{array}$ \\
\hline \multirow{2}{*}{ Day 1 } & MTA & 5 & .059 & .011 \\
\cline { 2 - 5 } & ERRM & 5 & .070 & .009 \\
\hline \multirow{2}{*}{ Day 7 } & MTA & 5 & .061 & .006 \\
\cline { 2 - 5 } & ERRM & 5 & .067 & .006 \\
\hline \multirow{2}{*}{21 st day } & MTA & 5 & .053 & .008 \\
\cline { 2 - 5 } & ERRM & 5 & .050 & .009 \\
\hline
\end{tabular}

\section{DISCUSSION}

Root-end filling materials are usually in contact with periradicular tissue fluid until they are eventually covered by fibrous connective tissue or cementoid [15].

Lack of solubility has also been stated as an ideal characteristic for root-end filling materials [16]. Solubility is the mass loss of a material during a period of immersion in water. Moreover, solubility may be a cause of disintegration or degradation of the root-end filling material, thereby leaving spaces that may provide gaps for bacterial colonization and their passage in periapical tissue [17].

In the current study, solubility was determined following the method outlined by Torabinejad, et al., [13]. The degree of solubility of test materials was determined by a modified method of the American Dental Association (ADA) specification \#30.

Solubility was measured as the difference between the initial weight and the weight at the end of each storage period. Consequently, a low solubility in distilled water as proposed in the Standard of the
International Standard Organisation (ISO) 6876: 2001 is required [18].

Mineral trioxide aggregate is a bioactive cement originally designed as an endodontic repair and root-end filling material with favourable physical properties and setting characteristics. Angelus MTA (Angelus, Londrina, Brasil) has an initial setting time of less than $10 \mathrm{~min}$, and a final setting time of less than 24 min was used in the current study [19].

In the current study, endosequence root repair material was more soluble than MTA in distilled water, Nevertheless, this increase was not statistically significant.

The difference in the degree of solubility between both materials can be attributed to a difference in composition. MTA-Angelus has low solubility because of an insoluble matrix of crystalline silica within itself that preserve its integrity even in the presence of water [20].

For MTA, difference between day 7 to day 21 $\mathrm{p}$ value was 0.046 . For ERRM difference between day 1 
to day 21 and day 7 to day $21 \mathrm{p}$ value was 0.043 and 0.041 respectively, with a increase in the solubility of both the materials on 21 days.

The solubilization of the MTA observed after 21 days most likely occurred because the bismuth oxide used as a radiopacifier increased the porosity of the material, thus also increasing its solubility, as reported in previous studies [21]. Different investigators reported different degrees of solubility for MTA. Nonetheless, most of them declared that MTA has low or no solubility [16]. There are no studies done on solubility of endosequence root repair material. EndoSequence Root Repair Material contains many of the same characteristics as BC sealer, with similar chemical composition .study done by poggio et al., showed Endosequence BC sealer showed higher solubility as a result of hydrophilic nanosized particles being present which increases their surface area and allows more liquid molecules to come into contact with them which can be compared with the current study [22].

However, Literature contains conflicting results: Viapiana et al., [23] found high solubility of MTA-Fillapex, while Zhou et al., [24] reported that solubility of the bioceramic sealer EndoSequence BC is consistent with ISO 6876:2001. The discrepancy between the results of these authors may be attributed to variations in the methods used to dry the samples after having subjected them to solubility testing. Although the methodology for ascertaining solubility closely mimics clinical situation, yet the results can only be partly transferred to a clinical situation. Only a part of the cements are exposed to the periapical fluids as against the study conditions where the surface area exposed to the aqueous environment is much greater [12]. All the materials were tested for solubility after they completely set; therefore, these test conditions differ from any clinical situation where the materials are used before their initial setting. As pointed out by Kaplan et al., [25] sealers when used in endodontic therapy come in contact with periapical fluids immediately; however, they are not completely immersed in it. A similar clinical scenario can be correlated to the use of root-end filling materials.

\section{CONCLUSION}

Within the limitations of the current study, it was found that there was no significant difference in solubility between endosequence root repair material and mineral trioxide aggregate.

There was significant difference between the time period of both MTA and ERRM which showed more solubility towards the end of study as compared to 1 and 7 days.

\section{REFERENCES}

1. Vasudev, S. K., Goel, B. R., \& Tyagi, S. (2003). Root end filling materials-A review. Endodontology, 15(2), 12-18.

2. Testori, T., Capelli, M., Milani, S., \& Weinsteind, R. L. (1999). Success and failure in periradicular surgeryA longitudinal retrospective analysis. Oral Surgery, Oral Medicine, Oral Pathology, Oral Radiology, and Endodontology, 87(4), 493-498.

3. Costa, A. T., Konrath, F., Dedavid, B., Weber, J. B. B., \& Oliveira, M. G. (2009). Marginal Adaptation of Root-end Filling Materials: An. The journal of contemporary dental practice, 10(2), 75-82.

4. Aqrabawi, J. (2000). Endodontics: Sealing ability of amalgam, super EBA cement, and MTA when used as retrograde filling materials. British dental journal, 188(5), 266-268.

5. Vivan, R. R., Zapata, R. O., Zeferino, M. A., Bramante, C. M., Bernardineli, N., Garcia, R. B., ... \& de Moraes, I. G. (2010). Evaluation of the physical and chemical properties of two commercial and three experimental root-end filling materials. Oral Surgery, Oral Medicine, Oral Pathology, Oral Radiology, and Endodontology, 110(2), 250-256.

6. Grossman, L. I. (1978). Solubility of root canal cements. Journal Dental Research, 57:927.

7. International Organization for Standardization. (2001). Specification for dental root canal sealing materials: ISO 6876. Geneva: International Organization for Standardization.

8. Janani Balachandran, G. (2013). Comparison of sealing ability of bioactive bone cement, mineral trioxide aggregate and Super EBA as furcation repair materials: A dye extraction study. Journal of conservative dentistry: JCD, 16(3), 247-251.

9. Marwah, N. (2014). The era of endodontic research Root-end filling materials. International Journal of Clinical Pediatric Dentistry, 7.

10. Lee, Y. L., Lee, B. S., Lin, F. H., Lin, A. Y., Lan, W. H., \& Lin, C. P. (2004). Effects of physiological environments on the hydration behavior of mineral trioxide aggregate. Biomaterials, 25(5), 787-793.

11. Alzraikat, H., Taha, N. A., \& Salameh, A. (2016). A comparison of physical and mechanical properties of Biodentine and Mineral Trioxide Aggregate. J Res Med Dent Sci, 4(2), 121-126.

12. Poggio, C., Lombardini, M., Alessandro, C., \& Simonetta, R. (2007). Solubility of root-endfilling materials: a comparative study. Journal of Endodontics, 33(9), 1094-1097.

13. Torabinejad, M., Hong, C. U., McDonald, F., \& Ford, T. P. (1995). Physical and chemical properties of a new root-end filling material. Journal of endodontics, 21(7), 349-353.

14. Danesh, G., Dammaschke, T., Gerth, H. U. V., Zandbiglari, T., \& Schäfer, E. (2006). A comparative study of selected properties of 
ProRoot mineral trioxide aggregate and two Portland cements. International Endodontic Journal, 39(3), 213-219.

15. Singh, S., Podar, R., Dadu, S., Kulkarni, G., \& Purba, R. (2015). Solubility of a new calcium silicate-based root-end filling material. Journal of conservative dentistry: JCD, 18(2), 149.

16. Owadally, I. D., Chong, B. S., Ford, T. P., \& Watson, T. F. (1993). The sealing ability of IBM® with the addition of hydroxyapatite as a retrograde root filling. Dental Traumatology, 9(5), 211-215.

17. Nguyen, T. N. (1994). Obturation of the root canal system. In: Cohen, S., Burns, R. C., editors. Pathways of the Pulp. 6th ed. St. Louis: Mosby; 219-71.

18. Kaup, M., Schäfer, E., \& Dammaschke, T. (2015). An in vitro study of different material properties of Biodentine compared to ProRoot MTA. Head \& face medicine, 11(1), 16.

19. Dawood, A. E., Parashos, P., Wong, R. H., Reynolds, E. C., \& Manton, D. J. (2017). Calcium silicate-based cements: composition, properties, and clinical applications. Journal of investigative and clinical dentistry, 8(2), e12195.

20. Torres, F. F. E., Bosso-Martelo, R., Espir, C. G., Cirelli, J. A., Guerreiro-Tanomaru, J. M., \& Tanomaru-Filho, M. (2017). Evaluation of physicochemical properties of root-end filling materials using conventional and Micro-CT tests. Journal of Applied Oral Science, 25(4), 374380.

21. Camilleri, J. (2011). Evaluation of the effect of intrinsic material properties and ambient conditions on the dimensional stability of white mineral trioxide aggregate and Portland cement. Journal of endodontics, 37(2), 239-245.

22. Poggio, C., Dagna, A., Ceci, M., Meravini, M. V., Colombo, M., \& Pietrocola, G. (2017). Solubility and $\mathrm{pH}$ of bioceramic root canal sealers: a comparative study. Journal of clinical and experimental dentistry, 9(10), e1189.

23. Viapiana, R., Flumignan, D. L., GuerreiroTanomaru, J. M., Camilleri, J., \& Tanomaru-Filho, M. (2014). Physicochemical and mechanical properties of zirconium oxide and niobium oxide modified $\mathrm{P}$ ortland cement-based experimental endodontic sealers. International endodontic journal, 47(5), 437-448.

24. Zhou, H. M., Shen, Y., Zheng, W., Li, L., Zheng, Y. F., \& Haapasalo, M. (2013). Physical properties of 5 root canal sealers. Journal of endodontics, 39(10), 1281-1286.

25. Kaplan, A. E., Goldberg, F., Artaza, L. P., De Silvio, A., \& Macchi, R. L. (1997). Disintegration of endodontic cements in water. Journal of endodontics, 23(7), 439-441. 